\title{
Do commercial real estate prices have predictive content for GDP?
}

\author{
Bert de Groot and Philip Hans Franses
}

Econometric Institute

Erasmus School of Economics

Econometric Institute Report 2012-12

\begin{abstract}
Using a uniquely compiled database concerning rental prices of commercial real estates, which are property of the largest broker in the Netherlands, we examine if these prices have predictive value for quarterly economic growth. In contrast to related studies, we document that the mean price contains no relevant information, whereas other properties of the price distributions have. We show that these distributions can be described by mixtures of two distributions, reflecting low-end and high-end price segments. Our main findings are that higher economic growth is predictable from more new buildings being rented, more variation in the price levels and a larger size of the low-price segment, while lower economic growth emerges when the differences in prices between high-end and low-end segments increase and when the average price level in the low-price segment increases.
\end{abstract}

This version: June 2012

Address for correspondence: Econometric Institute, Erasmus School of Economics, PO Box 1738, NL-3000 DR Rotterdam, franses@ese.eur.nl. Foremost, we are very grateful to DTZ Zadelhoff for providing us with the data. We also thank Bert de Bruijn and Siebe Versendaal for their help with compiling the database and some of the computations. 


\section{Introduction}

Real estate is a key factor in national economies. Real estate prices are closely monitored by financial investors and by economic decision makers, as these prices reflect sentiments and underlying values and as they might have predictive content for future economic conditions. A recent study of Miller et al. (2011) seems to be the first to examine, at an aggregate level, if house prices have predictive value for economic growth. There are various studies that, again at an aggregate level, study the link between house prices and consumption, see Benjamin et al. (2004), Kishor (2007) and Lettau and Ludvigson (2004) to mention a few, but no other studies exist concerning economic growth. In this paper we aim to add to the knowledge base by examining the predictive content of (non-residential) commercial real estate prices for future Gross Domestic Product (GDP) growth.

We focus on commercial real estate rental prices as we have access to a large and unique database, which was provided to us by the largest commercial real estate broker in the Netherlands, DTZ Zadelhoff. This is a unique opportunity as these data have never been analyzed as such. The quarterly data are available from 1983 onwards, and consists of rental prices (per square meter) of new office buildings and business units. A key aspect of our paper, that makes it different from related studies, is that we do not only consider mean prices but also other aspects of the distributions. In fact, as we shall demonstrate, the data for each quarter can be described by prices in two segments (high and low), and we take the properties of these segments into account. It is important to note that we do not manually and a priori divide the data in clusters associated with various types of buildings. Indeed, we could have looked at smaller offices, larges offices, offices in larger cities, business units and so on, but we decided not to do so. First, it could be that such finer data grids show less variation over time, and hence become less informative. Second, manual clustering amounts to making potentially arbitrary choices, and we prefer to let the data speak for themselves. Third, it is not clear whether financial decision makers, who may maintain various portfolios of property, have similar a priori clusters in mind. In sum, we put all data on all real estate together, and we let data-based clustering methods decide on the presence and characteristics of various clusters, if there are any,

Our main findings are that higher economic growth is predictable from more new buildings being rented, more variation in the price levels and a larger size of the low-price 
segment, while lower economic growth emerges when the differences in prices between highend and low-end segments increase and when the average price level in the low-price segment increases. We find that the reverse predictability only appears for the amount of new buildings rented, and that is that when GDP increases those amounts increase too, which of course does not come as a surprise.

The outline of our paper is as follows. In the next section we provide more details of the data, although for confidentiality reasons we cannot give all the details. In Section 3 we examine the relationships between GDP and commercial real estate prices, and we test predictability. In Section 4 we conclude with a discussion of the limitations, and we provide various further research issues.

\section{Data}

The data are from DTZ Zadelhoff brokers and they concern commercial real estate in the Netherlands. We have data at the individual property level since 1983 reported per month. As the GDP data will be observed at the quarterly level, we also compile the real estate data into quarters. For each case, we have the rental price per square meter (in Euros, where we use the conversion rate between the Dutch Guilder and the Euro for data before 2002). By far, DTZ Zadelhoff is the largest broker in the Netherlands, and as such the data can be assumed to representatively reflect the total population of commercial real estate.

In Figure 1 we present the amount of newly rented commercial real estate involved. Around 1990, there were about 150 new buildings being rented per quarter, while in 2000 this number went beyond 300 buildings. Recent data seem to be similar as in the nineteen eighties. The data also show some cyclical patterns with a dip in 1992-1994, relative to the boom in 19901991, and with a dip in 2002-2006, in between the booms of 1999-2001 and of 2007-2008.

Figure 2 shows the average rental prices (where the averages are taken across the observations within the quarters, which are not the same over time, see Figure 1) and the mean prices when corrected for inflation. These mean real prices seem to follow a similar shape as the data on amounts in Figure 1. Hence, apparently, when there is more commercial real estate being rented, prices are high too. This gives again the impression how substantial the boom was in and around 2000-2002. Profits in those days must have been huge. 
Figures 3 and 4 give an indication of the variance across the rental prices within each quarter. Figure 3 gives the differences between real maximum and minimum prices. The latter differences show a similar time series pattern in terms of periods with peaks and troughs. Figure 4 presents the standard deviation of the data within each quarter, and this looks rather similar to the pattern in Figure 3.

The graphs in these figures might suggest that the distributional properties of the data for each of the quarters are approximately similar over time. This is however not the case, and in contrast to other studies, we shall explicitly exploit that they are not. If we look at the (randomly selected) samples for 1990Q1, 2001Q4 and 2004Q1 in Figures 5 to 7, we clearly see that (1) the data do not obey normal distributions, and (2) that the distributional properties seem to change over time. For almost all samples of data for 1983Q1 to 2010Q2 we find that normality is rejected at low significance levels. In fact, most data seem to show the presence of mixtures of distributions. An economic argument for multi-modal price distributions is that these distributions can be associated with high-level rental prices (perhaps for commercial real estate located in downtown Amsterdam or Rotterdam or top-end office buildings) and lower-level rental prices (concerning rural towns or cities further away from the Dutch west coast area, but could also concern smaller business units).

To describe each of the quarterly distributions and to concisely summarize the properties, we experimented with fitting mixtures of K normal distributions to these data. The Eviews code is available upon request from the authors. We found that the most common outcome (based on the well-known Akaike's information criterion AIC and the Bayesian information criterion BIC) is that $\mathrm{K}$ is appropriately set at 2 . This means that each sample in each quarter may best be described by a mixture of two normal distributions, where we also allow the variance for each distribution to be different. In only two cases (2010Q1 and 2010Q2) we had to fix the variance to be common across the two distributions to obtain convergence.

If we denote the mean of the lower-price segment as $\mu_{1}$ (that is, the mean of the left-hand normal distribution) and the mean of the higher-price segment as $\mu_{2}$ (the right-hand normal distribution), then Figures 8 and 9 present the estimates of these parameters over time. Figure 10 gives the difference between the two means, where now the cyclical patterns in the data, which we observed in Figures 3 and 4 are less evident. Finally, Figure 11 gives the fraction of commercial real estate (as a number between 0 and 1) that can be associated with each of the two 
price segments. Interestingly, when mean prices go up at the turn of the century (see Figure 1), we see that this is apparently due to the prices in the low-price segment. This is because the fraction of real estate that is classified into the lower-price segment is very high in these years.

We conjecture that these more subtle data characteristics as in the last few graphs might perhaps be better in forecasting GDP than just the average prices. Finally, real GDP growth is given in Figure 12. We currently have reliable GDP figures for the sample starting in 1988Q1 and ending in 2008Q4. Of course, more recent data for GDP are available, but these are still subject to future revisions. Moreover, the revision process of data before 1988 has not yet been completed by Statistics Netherlands, and therefore the sample starts in 1988Q1.

\section{Modeling results}

To examine the forecasting properties of the real estate prices for quarterly GDP growth, we need a benchmark model. For that purpose, we create a simple time series model, where we use the familiar Lagrange Multiplier (LM)-based residual diagnostics (on first and first-to-fourth autocorrelation and first order ARCH, normality of the residuals), and the model fit and the significance of the estimated parameters to decide on the form of the proper model. The benchmark time series model appears to include one-quarter lagged growth and a moving average term at lag 4 . The estimation results are presented in Table 1, under the header I. The fit of this time series model is 0.760 , and the in-sample root mean squared prediction error (RMSE times 1000) is 6.996.

In the column with the header II in Table 1 we add the following variables (all one quarter lagged) to this time series model, and these are the natural log of the amount of buildings, the difference between the maximum and the minimum of the real prices, the mean of the real prices, the standard deviation, the estimated mean of the low-end price distribution and the similar mean of the high-end price distribution, and finally, the fraction of real estate in the lower price cluster. The aforementioned model diagnostics do not indicate any sign of misspecification, and hence we continue with this model. From the relevant column II we learn that the mean price and the mean price of the high-end segment are not significant. When we delete these variables, and re-estimate, we obtain the final estimation results in the column with header III. The fit of 
this model is now 0.820 , which compares favorably with the benchmark's 0.760 . Also, the AIC and BIC values show lower values, suggesting that the added variables provide substantial additional fit. Finally, the in-sample RMSE has dropped to 6.061, which amounts to a 13.4 decrease in forecast error.

Our main findings to be learned from model III are that higher economic growth is predictable from more new buildings being rented (0.007), more variation in the price levels (0.077) and a larger size of the low-price segment (0.005), while lower economic growth emerges when the differences in prices between high-end and low-end segments increase ($0.014)$ and when the average price level in the low-price segment increases $(-0.037)$. And, quite importantly, the mean prices, as is often used like in Miller et al. (2011), have no predictive value when other distributional characteristics of the data are included in the model.

A next question concerns the possibility that GDP might have predictive power for real estate rental prices, that is, is there any correlation the other way around? To that end, we follow the same procedure as above. We first fit simple time series models to the natural log of the amount of buildings, the difference between the maximum and the minimum of the real prices, the mean of the real prices, the standard deviation, the estimated mean of the low-end price distribution and the mean of the high-end price distribution, and finally, the fraction of real estate in the lower price cluster. The appropriate numbers of lags in an autoregressive (AR) model for these five variables appear to be 4, 2, 2, 1 and 0, respectively. Next, we add either current or onequarter lagged quarterly GDP growth. The relevant estimates appear in Table 2. Clearly, we see that only the natural log of the amount of buildings is somewhat correlated and predictable by GDP, but that the other aspects of the quarterly distributions cannot be predicted using GDP.

\section{Conclusion}

Using a uniquely compiled database concerning rental prices of commercial real estates, which are associated with the largest broker in the Netherlands, we have shown that commercial real estate prices do indeed have predictive content for future GDP growth. In contrast to related studies, we find that it is not the average price that generates the predictability, but that other features of the quarterly distributions of the rental prices have predictive value. This empirical 
finding is new to the extant literature. We thus believe that future research may wish to include similar features of data distributions when forecasting GDP or other macroeconomic aggregates like consumption and investment.

Naturally, even though our database is rather unique and has never been analyzed before, it obviously only concerns a single country. It may well be that in other countries other results prevail, but this is left for further research. 


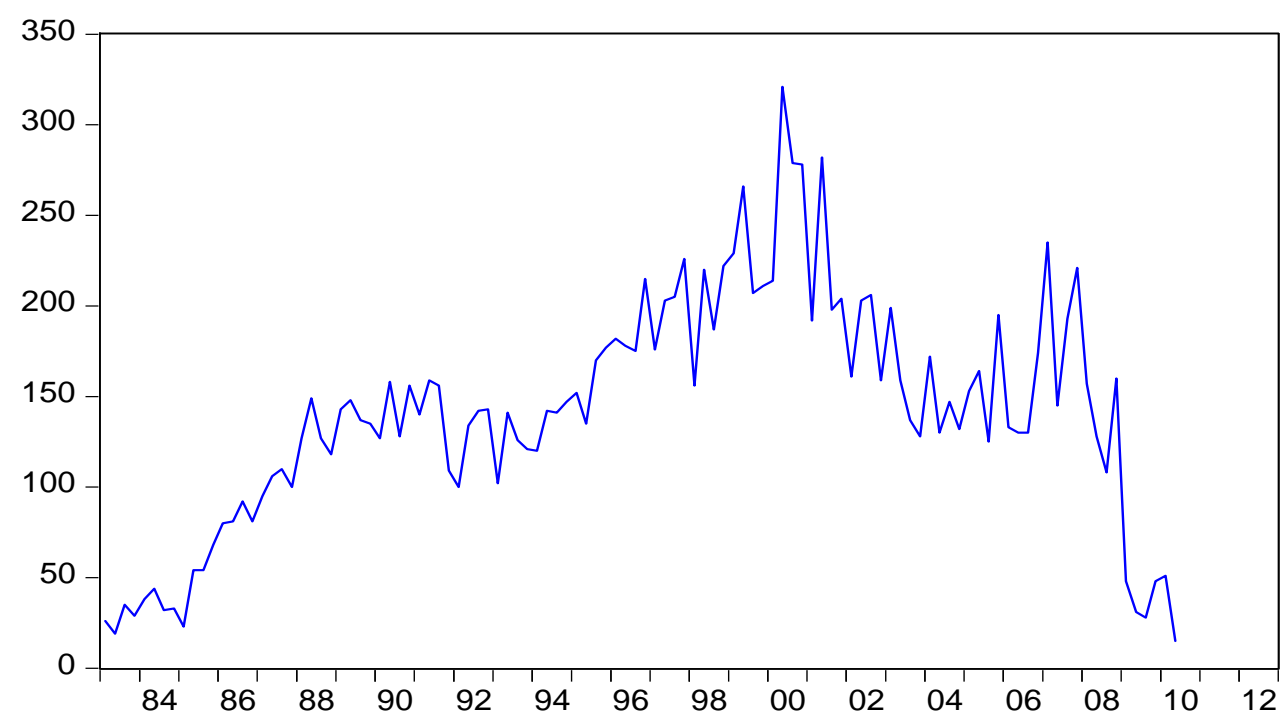

Figure 1: The amount of commercial office buildings for which rental prices are available (monthly data are collected into quarterly figures). The sample ranges from 1983Q1 to and including 2010Q2.

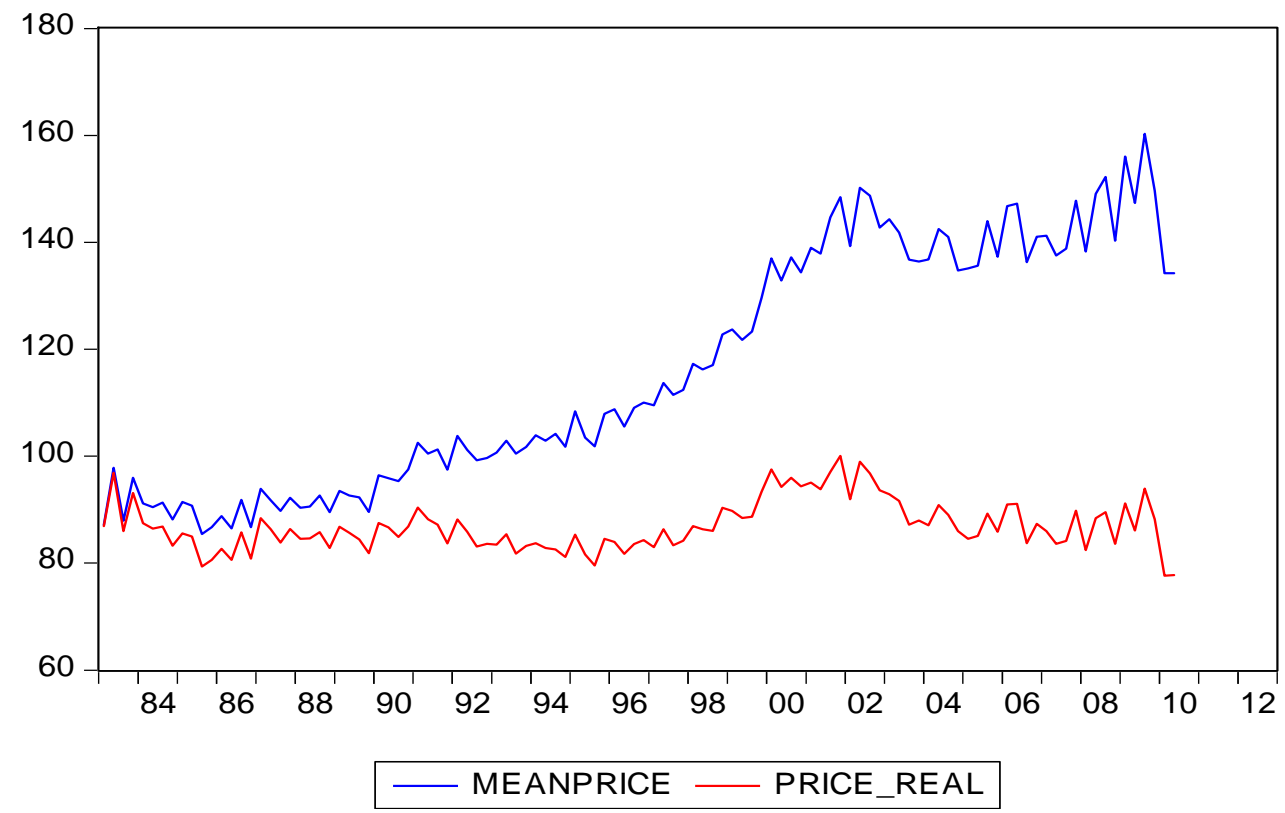

Figure 2: The mean of the rental prices (note that per quarter the sample is different, as depicted in Figure 1). The real price variable is the mean price when corrected for inflation 


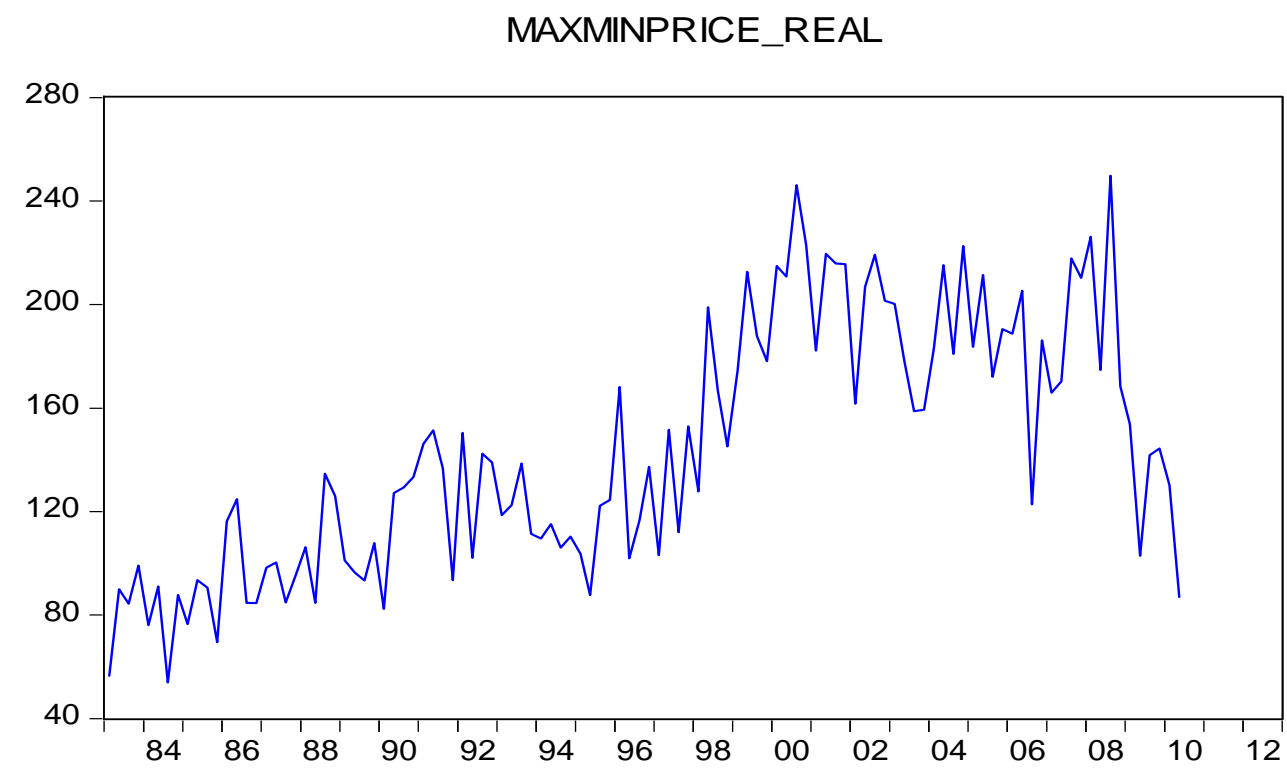

Figure 3: The difference between the maximum and the minimum prices (after correction for inflation)

SD_PRICE_REAL

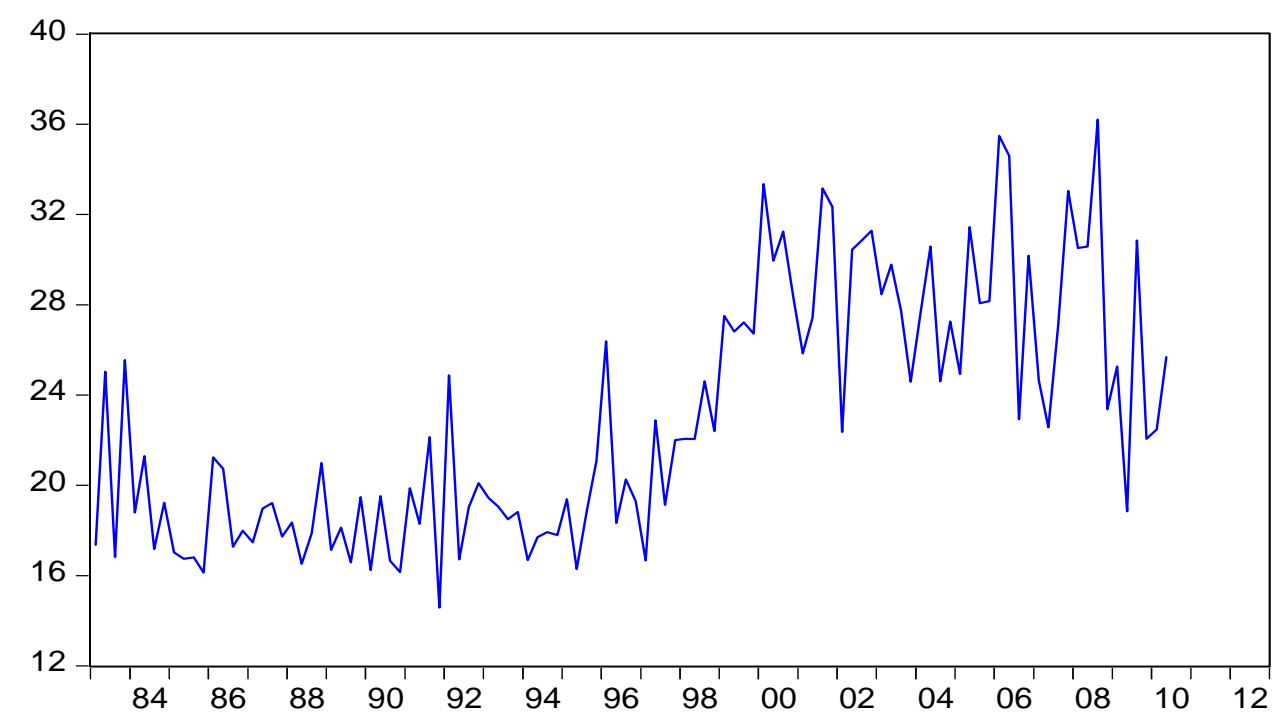

Figure 4: Standard deviation of the real price levels 


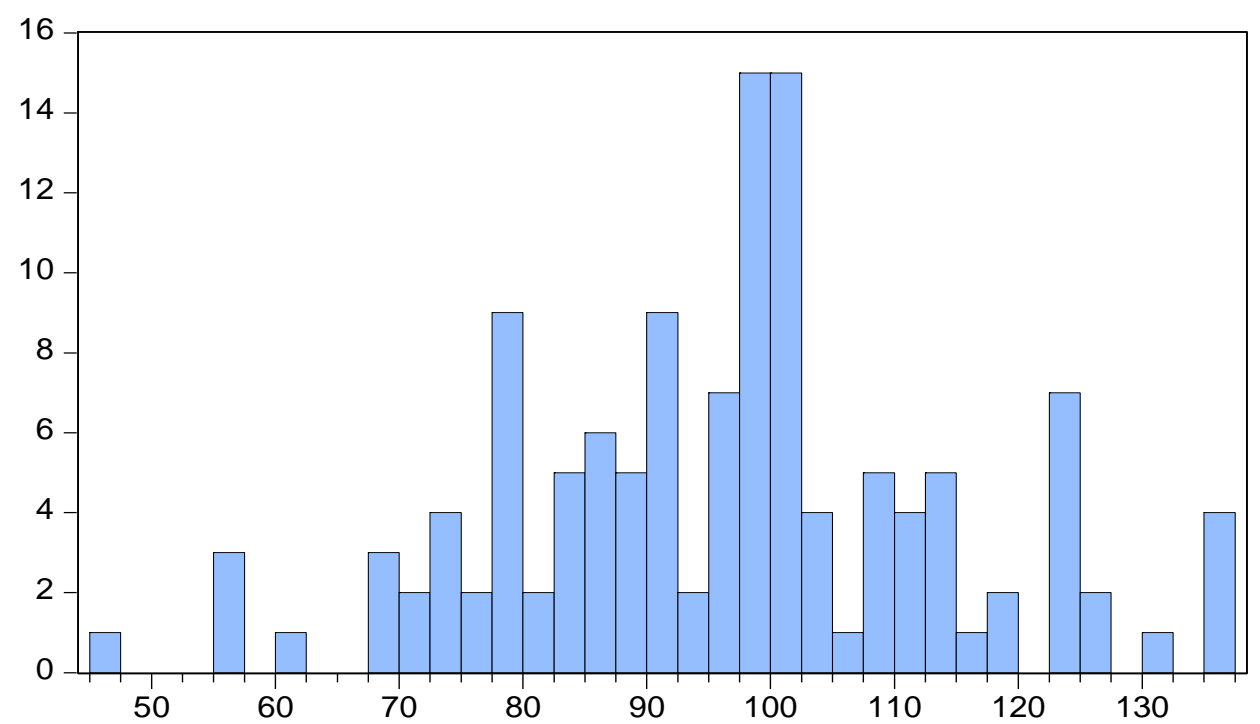

Figure 5: Rental prices in 1990Q1 (prices converted to Euros)

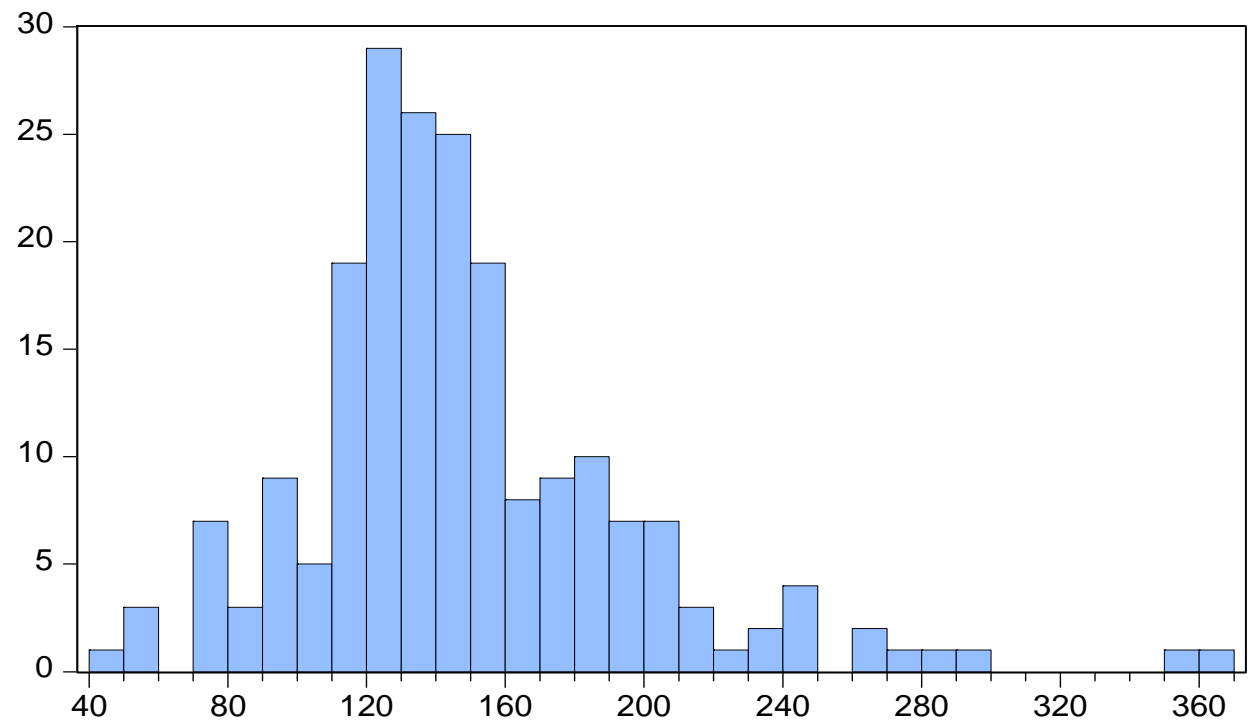

Figure 6: Rental prices in 2001Q4 (prices converted to Euros) 


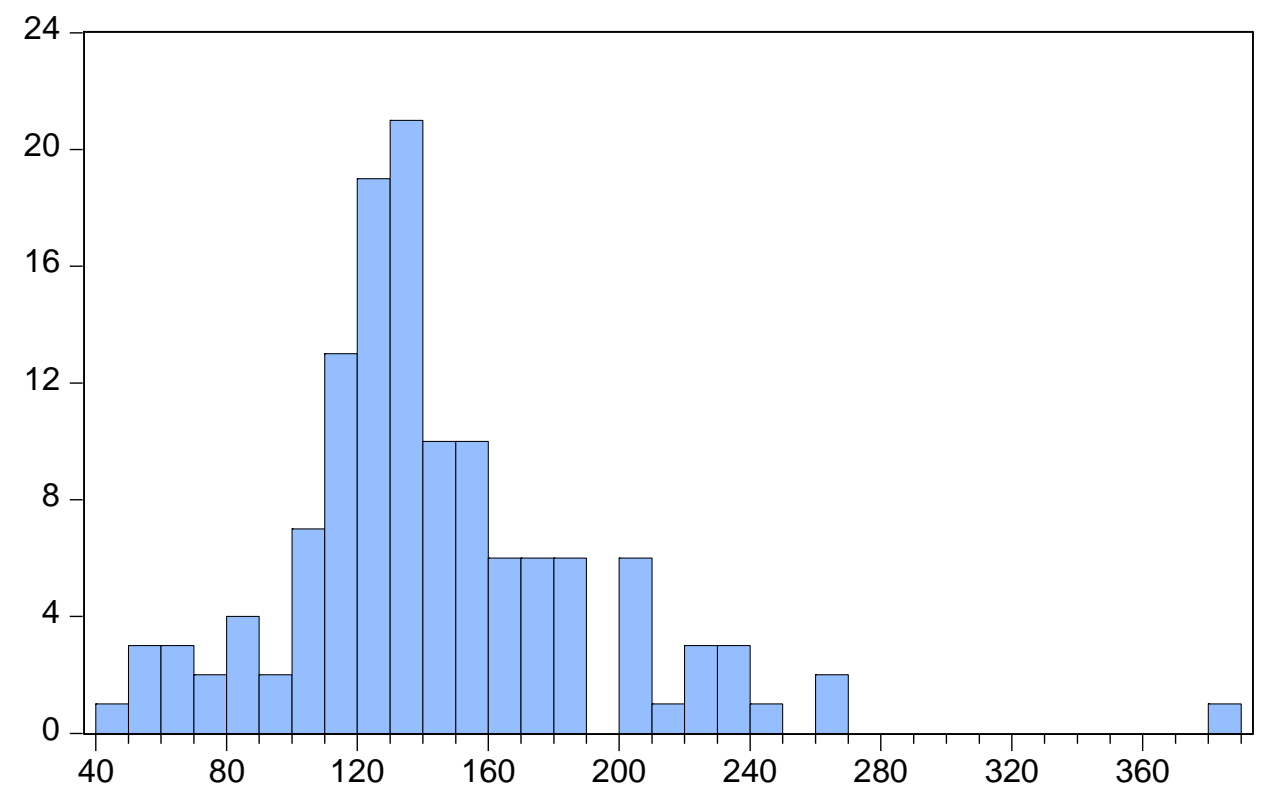

Figure 7: Rental prices in 2004Q1 (prices in Euros)

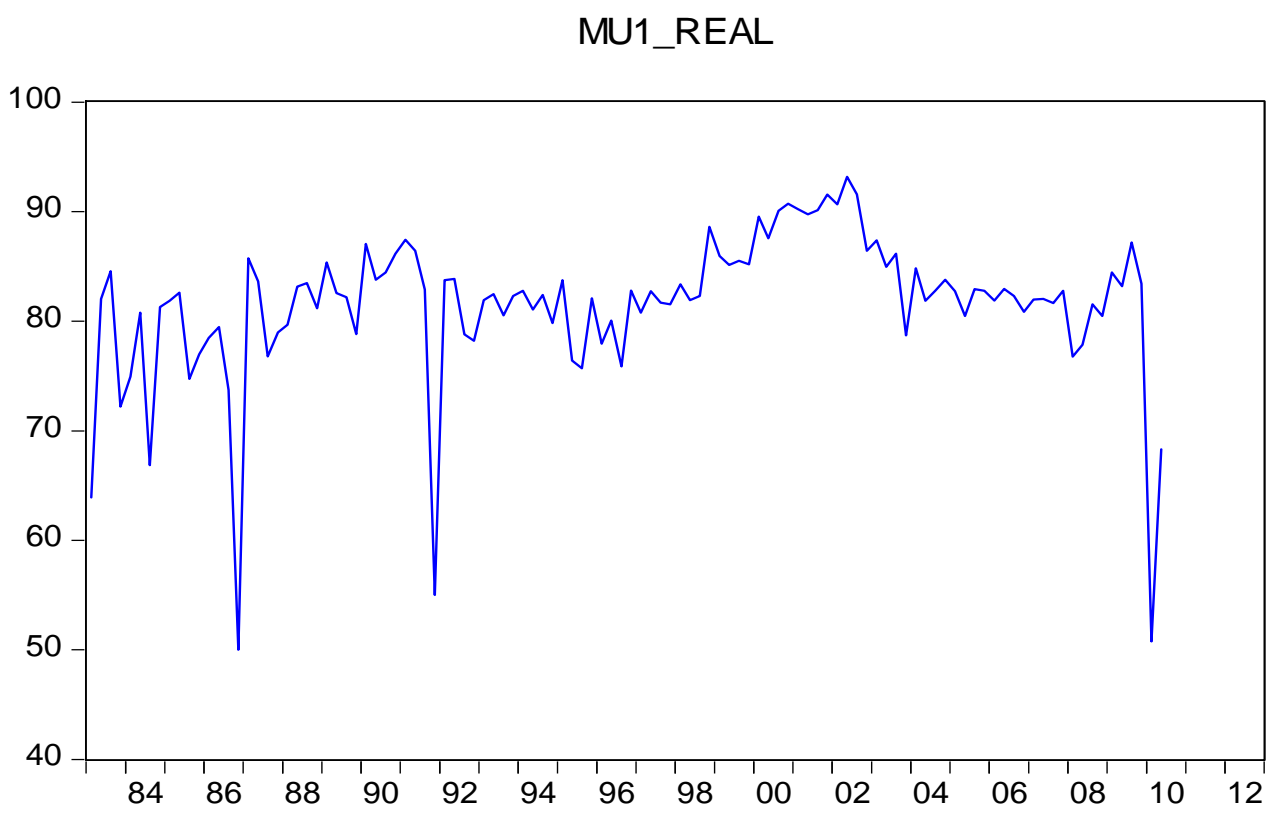

Figure 8: Estimated mean of the normal distribution for the lower-priced commercial real estates 
MU2_REAL

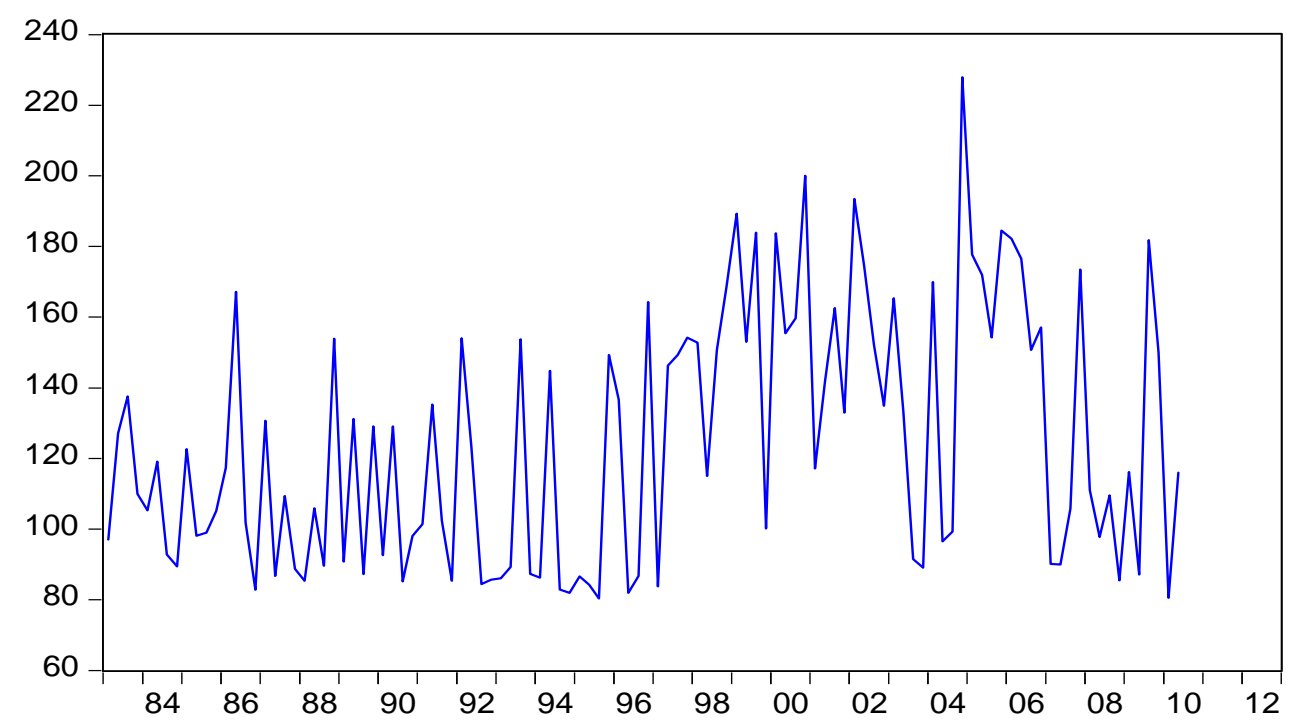

Figure 9: Estimated mean of the normal distribution for the high-priced commercial real estates

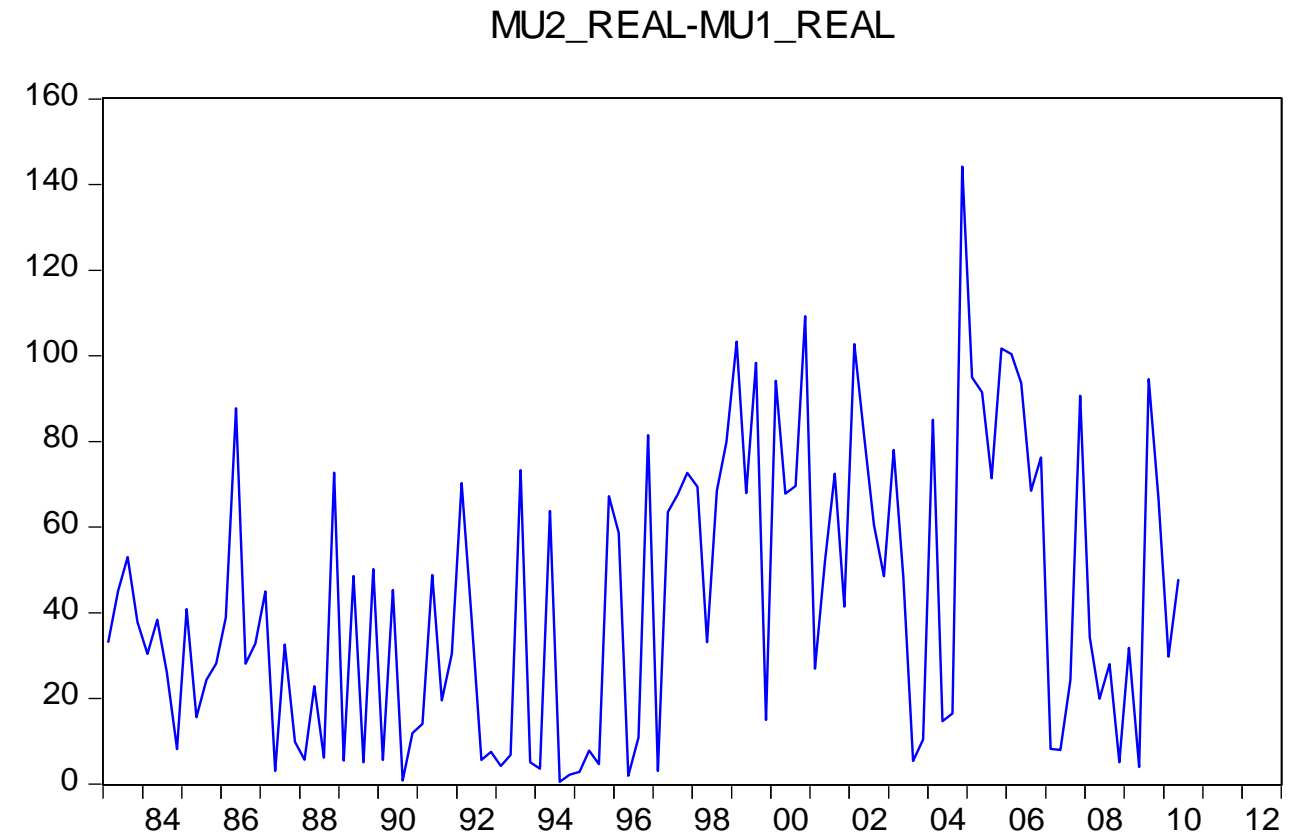

Figure 10: Difference between the estimated means of the normal distributions for the highpriced and lower-priced commercial real estates 
PROB1

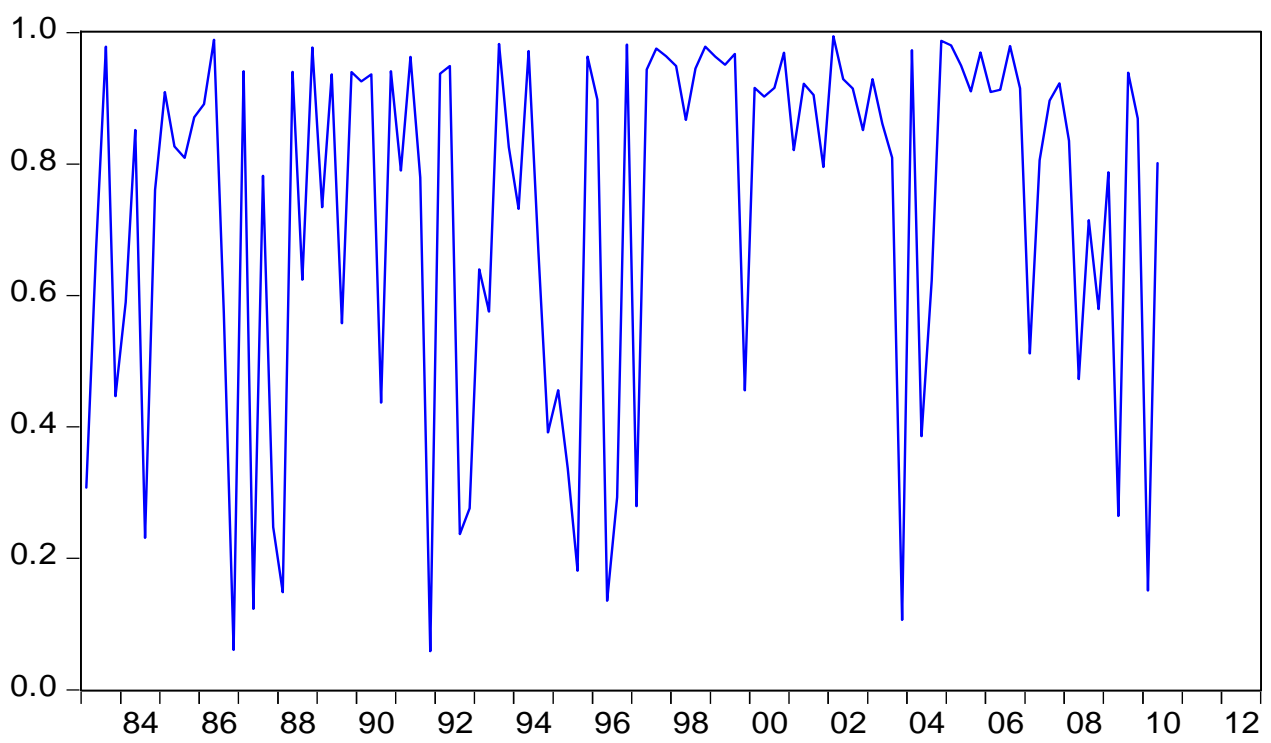

Figure 11: Estimated fraction of commercial real estates in the low-price segment

LOG(GDP_REAL)-LOG(GDP_REAL(-4))

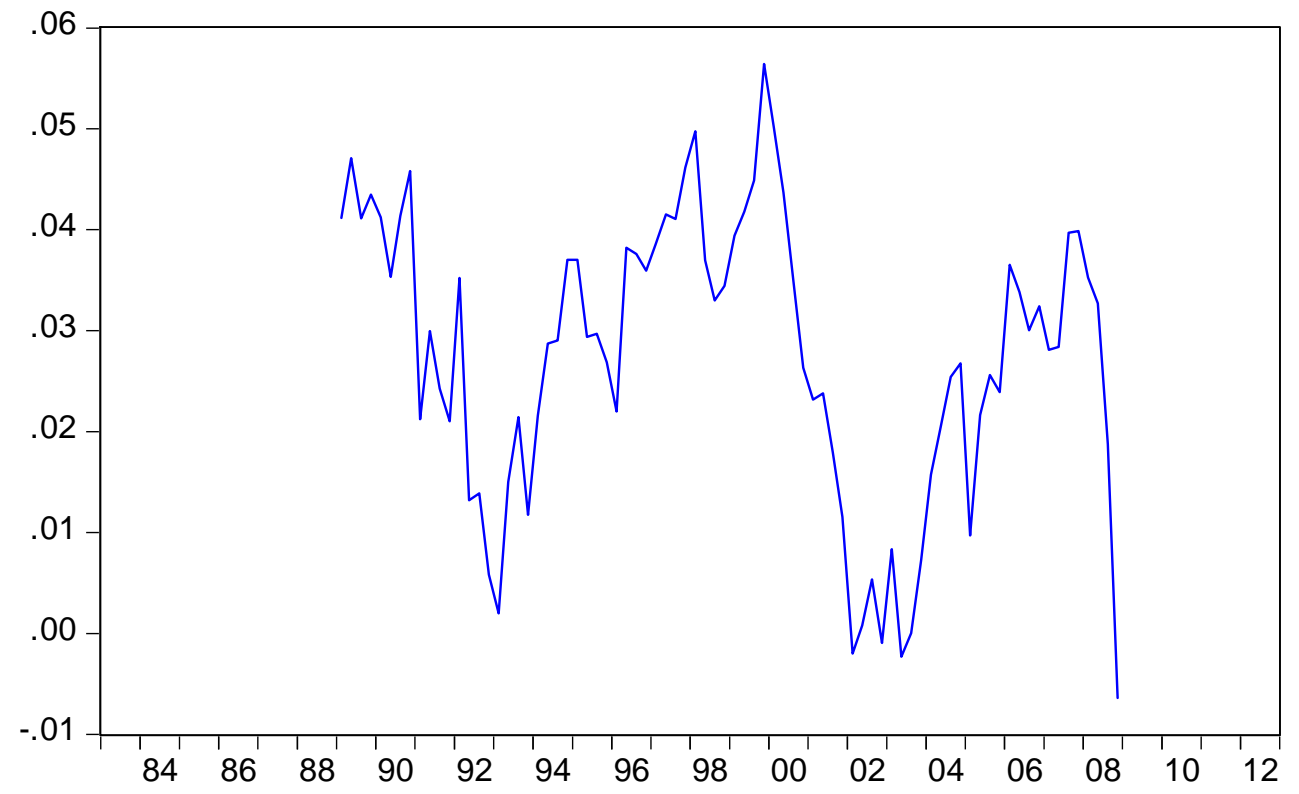

Figure 12: The variable to be explained: real GDP growth (annual) 
Table 1: Estimation results (the variable to be explained is real GDP growth, annual)

Estimation sample is 1989Q2 to and including 2008Q4 (79 observations). Numbers in parentheses are HAC corrected standard errors. Boldface numbers associate with significance at the $5 \%$ level.

\begin{tabular}{|c|c|c|c|}
\hline \multirow{2}{*}{ Variable } & I & II & III \\
\hline & & & \\
\hline Intercept & $0.001 \quad(0.001)$ & $-0.005(0.013)$ & $-0.003(0.020)$ \\
\hline Growth (t-1) & $0.964 \quad(0.038)$ & $0.824(0.052)$ & $0.836 \quad(0.050)$ \\
\hline MA(4) & $-0.910(0.027)$ & $-0.911(0.029)$ & $-0.915(0.030)$ \\
\hline $\log ($ amount) (t-1) & & $0.008 \quad(0.003)$ & $0.007(0.003)$ \\
\hline Max-Min real prices (t-1) (/100) & & $-0.014(0.004)$ & $-0.014(0.004)$ \\
\hline Mean real price (t-1) (/100) & & $-0.010(0.020)$ & \\
\hline St. dev. real price (t-1) (/100) & & $0.087 \quad(0.028)$ & $0.077 \quad(0.020)$ \\
\hline$\mu_{1}(\mathrm{t}-1)(/ 100)$ & & $-0.032(0.022)$ & $-0.037(0.012)$ \\
\hline$\mu_{2}(\mathrm{t}-1)(/ 100)$ & & $-0.001(0.002)$ & \\
\hline Fraction in lower price segment & & $0.006 \quad(0.004)$ & $0.005(0.002)$ \\
\hline R-squared & 0.760 & & 0.820 \\
\hline AIC & -7.011 & & -7.171 \\
\hline BIC & -6.921 & & -6.931 \\
\hline RMSE (x1000) & 6.996 & & 6.061 \\
\hline
\end{tabular}


Table 2: Are commercial real estate price variable correlated with GDP? Boldface numbers associate with significance at the $5 \%$ level.

Variable

$\log ($ amount)

Max-Min real prices (/100)

St. dev. real price (/100)

$\mu_{1}(/ 100)$

Fraction in lower price segment lags

GDP

3.416 (1.004)

2.998 (1.765)

$0.363 \quad(0.285)$

$0.041 \quad(0.031)$

$1.347 \quad(2.227)$
GDP(t-1)

4.992 (2.090)

$3.637 \quad$ (2.205)

$0.229 \quad(0.291)$

$-0.092(0.338)$

$2.156 \quad(2.032)$ 


\section{References}

Benjamin, J.D., P. Chinloy, and G.D. Jud (2004), Real estate versus financial wealth in consumption, Journal of Real Estate Finance and Economics, 29, 341-354.

Kishor, N.K. (2007), Does consumption respond more to housing wealth than to financial market wealth?, Journal of Real Estate Finance and Economics, 35, 427-448.

Lettau, M. and S. Ludvigson (2004), Understanding trend and cycle in asset values: reevaluating he wealth effect on consumption, American Economic Review, 94, 427-448.

Miller, N., L.Peng, and M. Sklarz (2011), House prices and economic growth, Journal of Real Estate Finance and Economics, 42, 522-541. 